Full Paper

\title{
Electrochemical Oxidation of Rutin
}

\author{
Mariana-Emilia Ghica, Ana Maria Oliveira Brett* \\ Departamento de Química, Faculdade de Ciências e Tecnologia, Universidade de Coimbra, 3004-535 Coimbra, Portugal \\ *e-mail: brett@ci.uc.pt
}

Received: March 9, 2004

Final version: June 8, 2004

\begin{abstract}
An electrochemical investigation of rutin oxidation on a glassy carbon electrode was carried out using cyclic voltammetry, differential pulse voltammetry and square-wave voltammetry over a wide $\mathrm{pH}$ interval. The electrochemical oxidation is a complex process, which proceeds in a cascade mechanism, related with the 4-hydroxyl groups of the rutin molecule. The catechol 3',4'-dihydroxyl group is the first to be oxidized by a two-electron - two-proton reversible oxidation reaction, followed by an irreversible oxidation reaction due to the 5,7-dihydroxyl group. Both mechanisms are $\mathrm{pH}$ dependent. An adsorption process is also observed and the oxidation products block the electrode surface.
\end{abstract}

Keywords: Rutin, Electrochemistry, Oxidation, Reduction, Adsorption process

\section{Introduction}

Flavonoids are a large family of polyphenolic compounds widely present in plants. Over the past decade, evidence has accumulated that flavonoids are an important class of antioxidants. They effectively suppress lipid peroxidation (LPO) in biological tissues and subcellular fractions, such as mitochondria, microsomes, liposomes, low-density lipoprotein (LDL), and erythrocyte membranes [1-4]. They also can act as antiproliferative agents to inhibit tumor growth, as weak oestrogen agents, or as antagonists to modulate endogenous hormone activity. Particularly confusing is the apparent paradoxical behavior of flavonoids in some situations, where they may behave as prooxidants or carcinogens.

All flavonoids are electroactive, easily subject to either oxidation or reduction electron transfer reactions, hence they can be investigated by electrochemical methods and flavonoids in beverages have been quantified by liquid chromatography with electrochemical detection (LC-ED) $[5,6]$. A detailed electrochemical study of four structurallyrelated flavonoids including rutin and quercetin, with identification of their oxidation products at a glassy carbon electrode has been reported [7, 8]. Fourteen flavonoid aglycones, and the flavonoid glycoside rutin were evaluated by cyclic voltammetry [9].

Rutin (quercetin-3-O-rutinose) is one of the most bioactive flavonoids, also known as vitamin $\mathrm{P}$ and was thought to be an activating factor for vitamin $\mathrm{C}$ [10]. Rutin is $3^{\prime}, 4^{\prime}, 5,7$-tetrahydroxyflavone-3 $\beta$-D-rutinoside and the corresponding chemical structure is given in Figure 1.

Some investigations showed that rutin has a broad range of physiological activities such as anti-inflammatory, antitumor and antibacterial. It is thought to improve capillary function by reducing abnormal leakage and has been<smiles></smiles>

Fig. 1. Structure of rutin.

administered to reduce capillary impairment and venous insufficiency of the lower limb [11].

The purpose of this study was to investigate the oxidation of rutin by electrochemical techniques, using cyclic, differential pulse and square-wave voltammetry, with respect to the $\mathrm{pH}$ dependent electron transfer process and the adsorption of rutin on the electrode.

\section{Experimental}

\subsection{Reagents and Solutions}

Rutin was purchased from Sigma-Aldrich, Madrid, Spain and was used as received without further purification. All solutions were made up using high-purity water from a Millipore Milli-Q system (resistivity greater than or equal to $18 \mathrm{M} \Omega \mathrm{cm})$. 
Table 1. Supporting electrolytes $0.2 \mathrm{M}$ ionic strength.

\begin{tabular}{rl}
\hline $\mathrm{pH}$ & Composition \\
\hline 1.3 & $\mathrm{HCl}+\mathrm{KCl}$ \\
2.0 & $\mathrm{HCl}+\mathrm{KCl}$ \\
3.5 & $\mathrm{HAcO}+\mathrm{NaAcO}$ \\
4.5 & $\mathrm{HAcO}+\mathrm{NaAcO}$ \\
5.3 & $\mathrm{HAcO}+\mathrm{NaAcO}^{-3}$ \\
6.0 & $\mathrm{NaH}_{2} \mathrm{PO}_{4}+\mathrm{Na}_{2} \mathrm{HPO}_{4}$ \\
7.0 & $\mathrm{NaH}_{2} \mathrm{PO}_{4}+\mathrm{Na}_{2} \mathrm{HPO}_{4}$ \\
8.0 & $\mathrm{NaH}_{2} \mathrm{PO}_{4}+\mathrm{Na}_{2} \mathrm{HPO}_{4}$ \\
9.2 & $\mathrm{NaOH}+\mathrm{Na}_{2} \mathrm{~B}_{4} \mathrm{O}_{7} \cdot 10 \mathrm{H}_{2} \mathrm{O}$ \\
11.9 & $\mathrm{NaOH}+\mathrm{KCl}$ \\
12.5 & $\mathrm{NaOH}+\mathrm{KCl}$ \\
\hline
\end{tabular}

A stock solution of rutin $(1.0 \mathrm{mM})$ was prepared in ethanol, its dissolution being facilitated by sonication. Solutions for analysis were prepared when needed by dilution of the stock solution to the desired concentration of $0.1 \mathrm{mM}$ with buffer just prior to use. The stock solution was kept in the refrigerator and was stable for at least one month.

Solutions of buffer supporting electrolyte of ionic strength $0.2 \mathrm{M}$ were used in all experiments, Table 1 , and were prepared using analytical grade reagents and purified water from a Millipore Milli-Q system (conductivity $\left.<0.1 \mu \mathrm{S} \mathrm{cm}^{-1}\right)$.

\subsection{Apparatus}

The electrochemical experiments were performed using an $\mu$ Autolab Type II running with GPES 4.9 (General Purpose Electrochemical System), software (Eco-Chemie, Utrecht, The Netherlands). The voltammograms were performed at room temperature in a three-electrode system (Cypress System, Inc., USA), consisting of a $1.5 \mathrm{~mm}$ diameter glassy carbon mini-electrode as working electrode, a platinum auxiliary electrode, and a saturated $\mathrm{Ag} / \mathrm{AgCl}$ in $3 \mathrm{M} \mathrm{KCl}$ reference electrode.

The cyclic voltammograms were performed at 25, 50, 100 and $200 \mathrm{mV} \mathrm{s}^{-1}$ scan rates. The conditions for differential pulse were: step potential $2 \mathrm{mV}$, pulse amplitude $50 \mathrm{mV}$, pulse width $70 \mathrm{~ms}$ and scan rate $5 \mathrm{mV} \mathrm{s}^{-1}$. Square-wave parameters were: step potential $2 \mathrm{mV}$ and pulse amplitude $50 \mathrm{mV}$. Square-wave voltammograms were recorded at 13 , 25, 50 and $100 \mathrm{~Hz}$.

The $\mathrm{pH}$ measurements were carried out with a Crison 2001 glass $\mathrm{pH}$-meter at room temperature.

\subsection{Procedure}

In order to obtain reproducible results and a constant surface of the working electrode, before recording each voltammogram a standard pretreatment procedure was applied. The electrode surface was smoothed by polishing with diamond spray ( 6 and $1 \mu \mathrm{m}$, Kemet International Ltd,
UK) and rinsed with ultrapure water. The state of the surface was monitored by running several cyclic voltammograms in supporting electrolyte.

\section{Results and Discussion}

The oxidation reaction of flavonoids is strongly related to their structure, which contains several free phenolic hydroxyl groups, particularly ortho-phenolic hydroxyl groups. The mechanism of electrooxidation of rutin involves ionization, losing a proton to give the monoanionic species followed by a one electron, one proton oxidation of the monoanionic species to form a radical anion. This then undergoes a second reversible one-electron oxidation to give dehydrorutin. The latter species is rapidly protonated and then dehydrated to yield the final product of $3^{\prime}, 4^{\prime}$-diquinone [12].

It has been shown that the antioxidant activity of flavonoids resides in their aromatic $\mathrm{OH}$ groups [13]. Rutin possesses four hydroxyl groups, which can be oxidized at carbon electrodes. The voltammetric behavior was investigated in the $\mathrm{pH}$ range 1.3 to 12.5 .

\subsection{Cyclic Voltammetry}

General information about the electroactivity and possible surface activity of various compounds is obtained from cyclic voltammetry. The cyclic voltammogram of $0.1 \mathrm{mM}$ rutin in $\mathrm{pH} 4.50 .1 \mathrm{M}$ acetate buffer solution, Figure 2, shows a reversible oxidation peak 1 at lower potentials, followed by an irreversible oxidation peak 2 at higher positive potentials.

The reversible oxidation peak 1 of rutin occurs at $E_{\mathrm{pa}}=$ $+0.460 \mathrm{~V}$, and corresponds to the oxidation of the $3^{\prime}, 4^{\prime}$-dihydroxy substituent on the ring-B of rutin. The

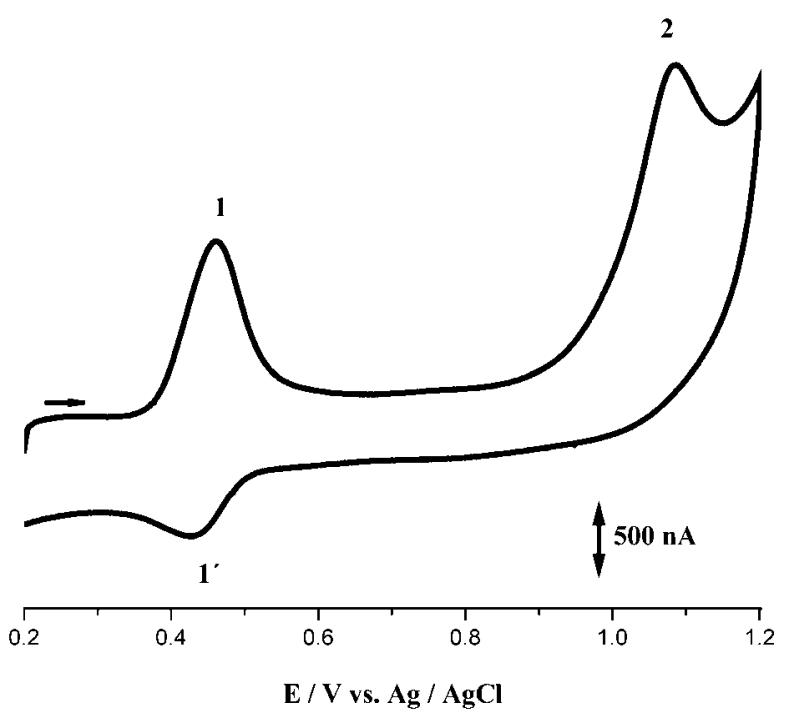

Fig. 2. Cyclic voltammogram of $0.1 \mathrm{mM}$ rutin in $\mathrm{pH} 4.50 .1 \mathrm{M}$ acetate buffer. Scan rate $100 \mathrm{mV} \mathrm{s}^{-1}$. 


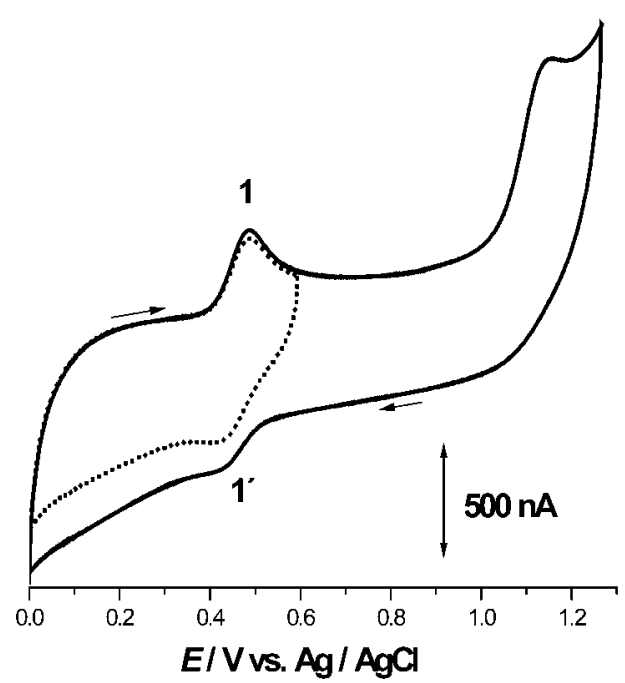

Fig. 3. Cyclic voltammogram of $0.1 \mathrm{mM}$ rutin in $\mathrm{pH} 4.50 .1 \mathrm{M}$ acetate buffer. (-) first scan between 0.0 and $+1.2 \mathrm{mV},(\cdots \cdots)$ second scan between 0.0 and $+0.55 \mathrm{~V}$. Scan rate $200 \mathrm{mV} \mathrm{s}^{-1}$.

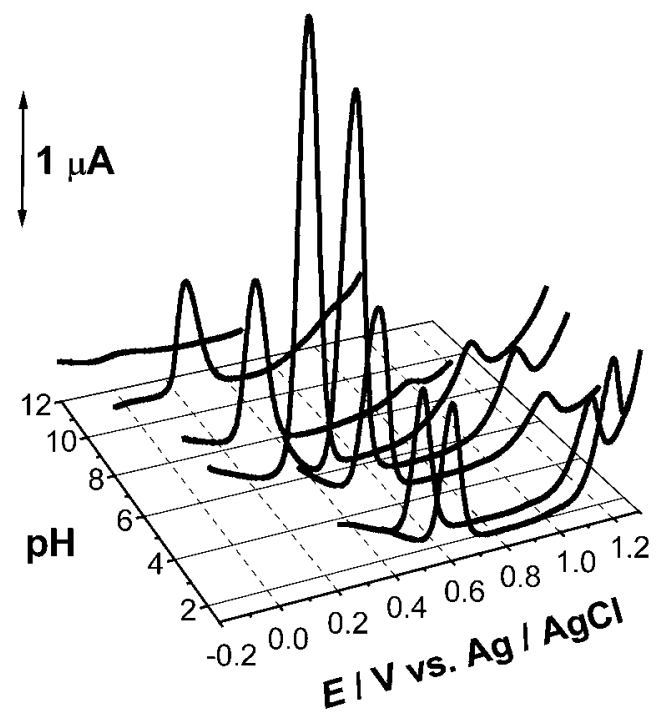

Fig. 4. 3D plots of differential pulse voltammograms of $0.1 \mathrm{mM}$ rutin as a function of $\mathrm{pH}$. Scan rate $5 \mathrm{mV} \mathrm{s}^{-1}$.

corresponding reduction peak of the $3^{\prime}, 4^{\prime}$-diquinone formed occurs at $E_{\mathrm{pc}}=+0.432 \mathrm{~V}$. The peak separation is $\Delta E_{\mathrm{p}}=$ $E_{\mathrm{pa}}-E_{\mathrm{pc}}=28 \mathrm{mV}$. The small peak separation suggests a relatively fast sequence of electrode reactions involving reversible transfer of two electrons, on the glassy carbon electrode.

The reversibility of the first peak 1 was more noticeable at $\mathrm{pH} 4.5$, Figure 3, when the scan potential was inverted immediately after the first peak, although the reduction peak was always visible, but smaller, even after the second oxidation.

The second oxidation, peak 2 , occurred at $E_{\mathrm{pa}}=+1.08 \mathrm{~V}$, corresponding to an irreversible reaction which involves the

Electroanalysis 2005, 17, No. 4
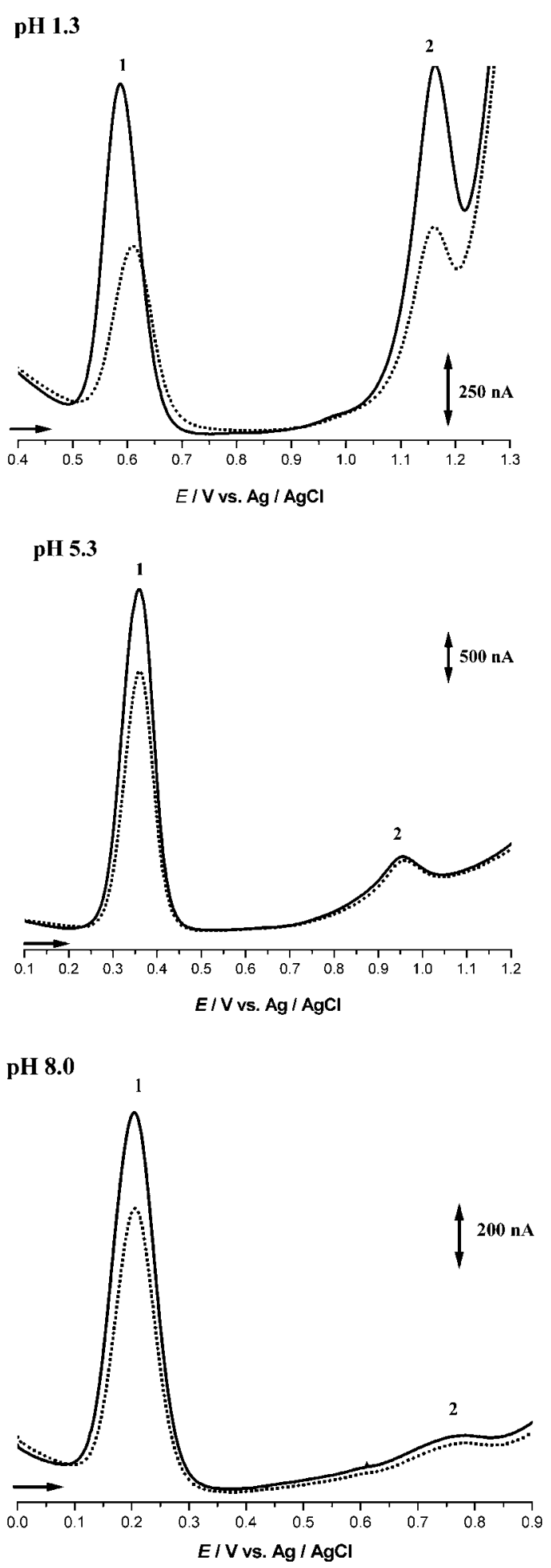

Fig. 5. Differential pulse voltammograms for oxidation of $0.1 \mathrm{mM}$ Rutin, (-) first and $(\cdots \cdots)$ second scans, in different supporting electrolytes. Scan rate $5 \mathrm{mV} \mathrm{s}^{-1}$.

5,7-dihydroxy group. Rutin was also adsorbed strongly on the electrode surface and this adsorption process was observed with all the voltammetric methods used. 


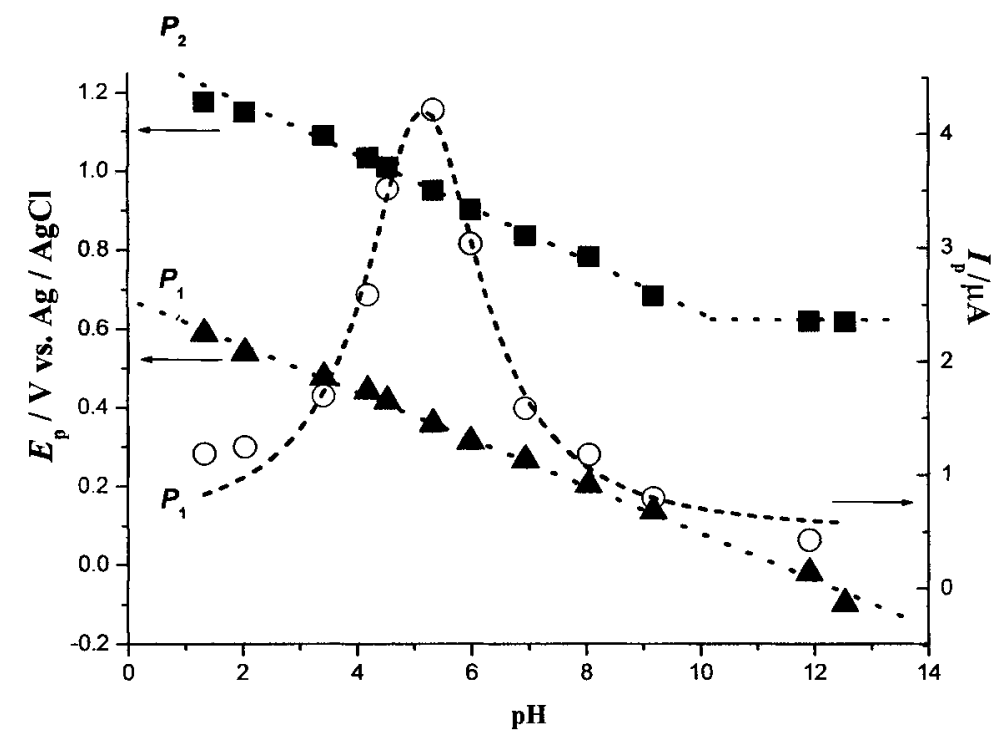

Fig. 6. Dependence on buffer supporting electrolyte $\mathrm{pH}$ of rutin oxidation peak current, $I_{\mathrm{p}}$, of $(\mathrm{O})$ peak $1\left(P_{1}\right)$, and of peak potential, $E_{\mathrm{p}}$, of $(\mathbf{\Lambda})$ peak $1\left(P_{1}\right)$ and $(\mathbf{\bullet})$ peak $2\left(P_{2}\right)$. Dotted lines corresponds to a slope of $59 \mathrm{mV}$ per unit of pH. Data from Figure 4.

\subsection{Differential Pulse Voltammetry}

The dependence of the electrochemical oxidation of rutin on the $\mathrm{pH}$ was studied by differential pulse voltammetry. The effect of $\mathrm{pH}$ was studied by varying the $\mathrm{pH}$ of the supporting electrolyte from 1.3 up to 12.5 . The results obtained are shown in Figure 4, which is a 3D plot of differential pulse voltammograms as a function of $\mathrm{pH}$. There is an enhancement of the peak currents in the acidic region. A two-step electron transfer reaction occurs at all $\mathrm{pH}$ values, associated with the loss of two protons. At high $\mathrm{pH}$ only one proton is lost resulting in a lower current [14]. The strong adsorption of rutin's oxidation products was confirmed since the oxidation peaks decreased drastically in the second scan for all pHs, Figure 5.

Two anodic peaks were observed at all values of $\mathrm{pH}$. The current of the first reversible peak increased with increasing $\mathrm{pH}$ in acidic solution, the maximum current being obtained at $\mathrm{pH} 5.3$, and afterwards the current decreased with increasing $\mathrm{pH}$. The current of the second oxidation peak decreased up to $\mathrm{pH}$ 9.2; when it almost disappeared.

Correlation of the flavonoid structure with the corresponding $E_{\mathrm{p}}$ values reveals that the oxidation occurs at lower potentials in the case of flavonoids containing more free phenolic hydroxyl groups and particularly in the orthoposition, in either ring, whereas the presence of a carbohydrate moiety hinders this oxidation shifting the $E_{\mathrm{p}}$ values to more positive values [15].

The variation of the peak potential, $E_{\mathrm{p}}$, with $\mathrm{pH}$ can provide valuable information on the electrode process. From the slope of a plot of $E_{\mathrm{p}}$ vs. pH, Figure 6, a linear regression equation $E_{\mathrm{p} 1}=0.670-0.059 \mathrm{pH}$ was obtained for peak 1 and $E_{\mathrm{p} 2}=1.27-0.061 \mathrm{pH}$ up to $\mathrm{pH} 9.2$ for peak 2 . Therefore it can be concluded that the same number of the protons and electrons was involved in both electrode reactions. Consequently, the first oxidation of rutin in this case is a two-proton two-electron reversible electrochemical reaction with both reactant and product adsorbed on the electrode surface [16]. The products of oxidation of flavonoid rutin can also undergo homogenous chemical reactions with the water following its oxidation at a glassy carbon electrode.

\subsection{Square-Wave Voltammetry}

Experiments by square-wave voltammetry were carried out over the same $\mathrm{pH}$ range. Square-wave voltammetry showed similar results to differential pulse and cyclic voltammetry. This method presents some advantages such as lower consumption of electroactive species and consequent diminishing of the species which are blocking the electrode surface. Nevertheless, it can be observed that adsorption occurs in the second and third scan, Figure 7, and also there is an increase of the peak 1 current with increasing $\mathrm{pH}$ in acidic media, then decreasing in alkaline media. The peak 2 current decreases continuously with $\mathrm{pH}$ until $\mathrm{pH}$ 9.2, and then almost disappears.

One of the most important advantages of square-wave voltammetry is that with this method the reversible character of the electron transfer reaction can be checked during the scan. Since the current is sampled in both the positive and the negative-going pulses, peaks corresponding to oxidation or reduction of the electroactive species at the electrode surface can be obtained at the same time.

In Figure 8 the forward and backward currents are shown and the oxidation and reduction peaks occur at the same potential, $E_{\mathrm{p}}=+0.645 \mathrm{~V}$, this confirms the reversibility of the first oxidation peak of rutin. These characteristics are no longer present for the second oxidation peak in agreement 

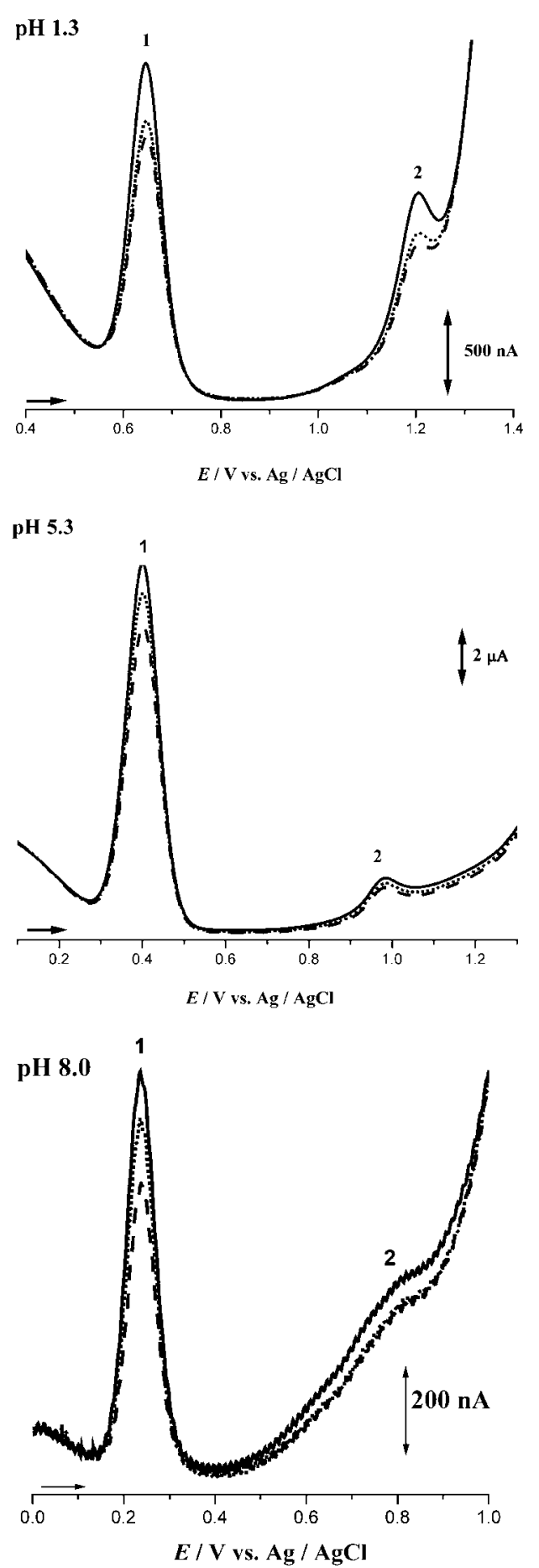

Fig. 7. Square-wave voltammograms for oxidation of $0.1 \mathrm{mM}$ rutin in different supporting electrolytes: $(-)$ first, $(\cdots \cdots)$ second, and (---) third scans. Frequency $25 \mathrm{~Hz}$, amplitude $50 \mathrm{mV}$.

with the conclusion that the second oxidation reaction is not reversible.

These results compare very well with those obtained for the same $\mathrm{pH} 1.3$ using differential pulse voltammetry (see Fig. 5).

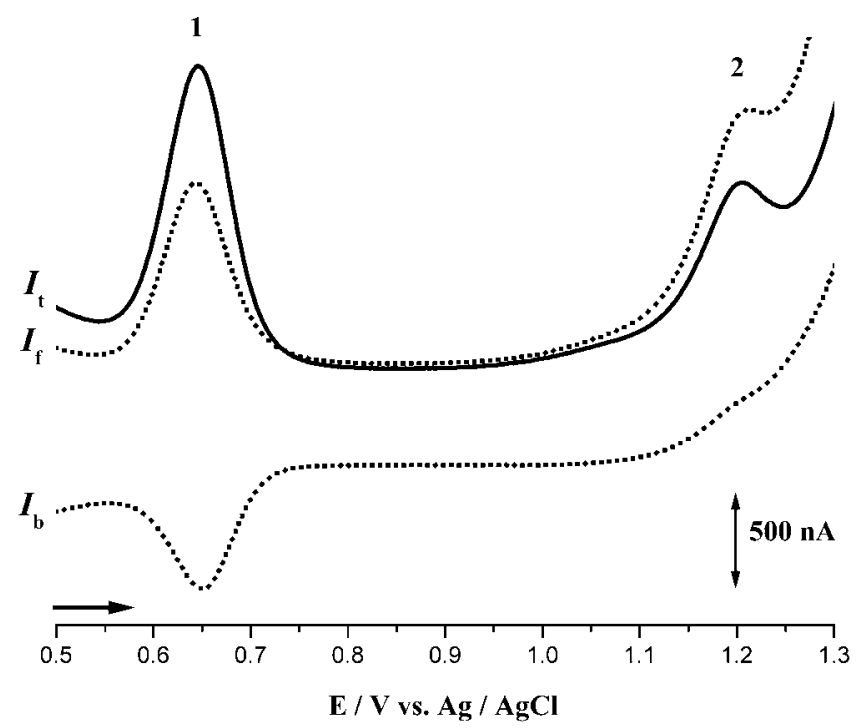

Fig. 8. Square-wave voltammograms for oxidation of $0.1 \mathrm{mM}$ rutin in $\mathrm{pH} 1.3$ supporting electrolyte: $I_{\mathrm{t}}$ : total current, $I_{\mathrm{f}}$ : forward current, $I_{\mathrm{b}}$ : backward current. Frequency $25 \mathrm{~Hz}$, amplitude $50 \mathrm{mV}$.

\section{Conclusions}

The experimental results demonstrate that using electrochemical methods, cyclic voltammetry, differential pulse voltammetry and square-wave voltammetry, the mechanism of electron transfer of rutin can be clarified. The study reveals that it is a complex and $\mathrm{pH}$-dependent process. As can be seen, rutin is strongly adsorbed on the electrode surface, the oxidation products blocking the surface of the electrode. The experiments showed a reversible process corresponding to oxidation of the catechol $3^{\prime}, 4^{\prime}$-dihydroxyl group and another irreversible at high potentials corresponding to the oxidation of the 5,7-dihydroxyl groups.

\section{Acknowledgements}

Financial support from Fundação para a Ciência e Tecnologia (FCT), POCTI (cofinanced by the European Community Fund FEDER), ICEMS (Research Unit 103) and European Projects QLK3-2000-01311 and HPRN-CT-200200186 are gratefully acknowledged.

\section{References}

[1] T. Okuda, Y. Kimura, T. Yoshida, T. Hatano, H. Okuda, S. Arichi, Chem. Pharm. Bull. 1983, 31, 1625.

[2] J. Terao, M. Piskula, Q. Yao, Arch. Biochem. Biophys. 1994, 308, 278.

[3] N. Salah, N. J. Miller, G. Paganga, L. Tijburg, G. P. Bolwell, C. Rice-Evans, Arch. Biochem. Biophys. 1995, 322, 339.

[4] T. B. Ng, F. Liu, Z. T. Wang, Life Sci. 2000, 66, 709.

[5] S. M. Lunte, K. D. Blankenship, S. A. Read, Analyst 1988, $113,99$.

[6] S. M. Lunte, J. Cromatogr. 1987, 384, 371.

(c) 2005 WILEY-VCH Verlag GmbH \& Co. KGaA, Weinheim 
[7] H. P. Hendrickson, A. D. Kaufman, C. E. Lunte, J. Pharm. Biomed. Anal. 1994, 12, 325.

[8] H. P. Hendrickson, M. Sahafayen, M. A. Bell, A. D. Kaufman, M. E. Hadwiger, C. E. Lunte, J. Pharm. Biomed. Anal. 1994, 12, 335.

[9] L. V. Jorgensen, L. H. Skibsted, Free Radical Res. 1998, 28, 335.

[10] N. E. Zoulis, C. E. Efstathiou, Anal. Chim. Acta 1996, 320, 255.

[11] J. E. F. Reynolds, Martindale, The Extra Pharmacopoeia, 31st ed., The Royal Pharmaceutical Society, Council of the Royal
Pharmaceutical Society of Great Britain, London 1996, pp.1679-1680.

[12] J. Kang, X. Lu, H. Zeng, H. Liu, B. Lu, Anal. Lett. 2002, 35, 677.

[13] C. G. M. Heijnen, G. R. M. M. Haenen, J. A. J. M. Vekemans, A. Bast., Environ. Toxicol. Pharmacol. 2001, 10, 199.

[14] S. A. B. E. Van Acker, M. J. De Groot, D. J. Van den Berg, M. N. J. L. Tromp, G. Donne-Op den Kelder, W. J. F. Van der Vijgh, A. Bast, Chem Res. Toxicol. 1996, 9, 1305.

[15] G. J. Volikakis, C. E. Efstathiou, Talanta 2000, 51, 775.

[16] X. Bao, Z. Zhu, N. Q. Li, J. Chen, Talanta, 2001, 54, 591. 